\title{
INTRODUCTION OF ONLINE-BASED ACCOUNTING RECORDING SYSTEM FOR SMALL AND MEDIUM ENTERPRISES
}

\author{
Hendi Prihanto, Meiliyah Ariani, Dwi Prihatini, Watriningsih \\ Universitas Prof. Dr. Moestopo (Beragama), Indonesia. \\ hp_torana@yahoo.com
}

\begin{abstract}
Industrial Revolution 4.0 demands every person, in the modern era and full of digitalization to have advantages and uniqueness in order to lead them to win competitions. The existence of many kinds of accounting-based supporting software technology if used properly will bring its users to a profit that can not only minimize the risk of financial statements from materiality, but also the use of human resources. This PKM aims to provide understanding to all parties (the community, students and business people) so that they are skilled in bookkeeping using internet-based accounting software that is low at cost, practical, and safe in doing business. This is because at this time the business world is strongly influenced by information technology, so innovation and learning are needed for the community in advancing the understanding and use of IT. The results of the activity provides understanding and at the same time knowledge to users that will be used practically in business activities, so as to be able to contribute through its operations that help their business development through preparing precise and fast financial statements in providing information for decision making. This activity provides enormous benefits for the community, especially those who pursue entrepreneurial activities because they are effective in their implementation, for that it needs to be done on an ongoing basis in the future by using existing and newer software.
\end{abstract}

Keywords: "Jurnal” Accounting Software, TAM Theory, Industry 4.0

\section{INTRODUCTION}

The flow of globalization has been unstoppable into Indonesia, accompanied by the emergence and development of increasingly sophisticated technology. The world is now entering the era of the industrial revolution 4.0, emphasizing the pattern of digital economy, artificial intelligence, big data, robotic, etc., or in learning technology and information systems more often known as disruptive innovation phenomena (http://sumberdaya.ristekdikti.go.id, 30-01-2018)). To face these challenges, universities have a significant role in producing quality human resources in the future, especially in the sector of digitalization.

One of the studies in accounting is how technology is able to play a role in helping users to carry out work without obstacles that make it difficult and ultimately will slow down financial reporting in decision making for management. "Jurnal" recording application is an online accounting application service that is safe and reliable for small and medium enterprises, as in using the "Jurnal", users do not need to download or install anything on their computers. In addition, they also do not need to pay to start or upgrade it, because the Jurnal will update it for free and automatically. What to do is just to register, $\log$ in, and they can do business bookkeeping created by the users. (https://www.jurnal.id/id/blog/2018). Some advantages of using this Jurnal application are as follows:

Making complete reports faster. By using the Jurnal, financial management and recording will be faster. What users need to do is to record all business transactions in the Jurnal, and the system will help users in making complete financial statements automatically; income statement, balance sheet, cash flow, purchase-sales, and many more. Only by recording the transaction once, the users can get all the financial statements needed anytime, anywhere. In other words, this application provides a high degree of flexibility.

More accurate $\&$ reliable. This accounting application has a higher level of accuracy compared to using a calculator or manual calculation. Calculation with manual system will be vulnerable to writing errors while the accounting application is not, so with the accounting application, any recording or addition will be more accurate.

Risk of errors is reduced. In making financial statements, users may have made errors, in recording transactions, or entering the nominal. In manual system, this will certainly bother them. However, with Jurnal accounting application, they only need to edit them and the financial statements they get will be updated automatically without having to repeat the process from the start.

Can be reviewed at any time. The cloud features in Jurnal accounting application will enable the users to access financial statements wherever and whenever using smartphones or tablets. Therefore, users can review and show the file or financial information without having to search the physical archive file. In addition, the accessible file or financial information may be in the form of old or new files.

Easy to use. This accounting application is very easy to use, users only need to have and master the ability to operate computers and understand accounting procedures or accounting standards for using accounting 
applications. Thus, everyone can use it, not only for accounting or computer experts.

Technology Acceptance Model (TAM) is a model of receiving information technology systems that will be used by users. TAM was developed by Davis et al (1989) based on the TRA model. TAM adds two main constructs to the TRA model. These two main constructs are perceived usefulness and perceived ease of use. These can then be described in the TAM framework as follows:

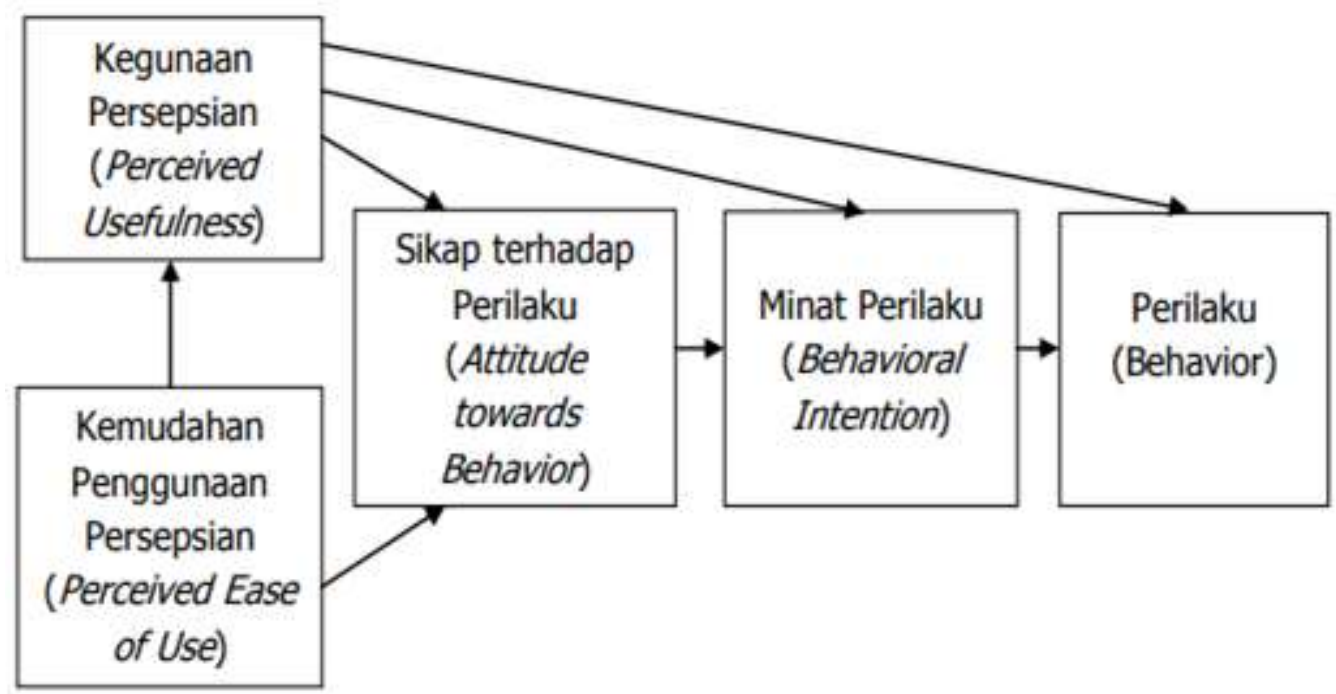

Figure 1. Figures of TAM model technology users

The theory assumption illustrates the ease of use of technology that will result in responses to attitudes, interests and then the behaviors of users resulting from using the tool. For this purpose, the community service aims to introduce and provide training to the community about the ease of using "Jurnal" software to all parties. This activity is expected to provide benefits to the community especially business owners such as MSMEs or even their employees in using tools that facilitate the implementation of their activities, provide security and convenience, and ultimately provide ease in retrieving business information through the use of online-based accounting software. The second target is to change the community's view of accounting which has been difficult but very easy and practical, so that people will be more interested in learning accounting in the future.

\section{IMPLEMENTATION METHOD}

The targets in this activity are the community, students and MSMEs around Palmerah, West Jakarta, who are selected according to the community service team to be given training in these activities. The method of delivering information is done by lectures (training) and question and answer interspersed with cases, examples and previously given a review of knowledge about the basic knowledge relating to recording financial transactions. Therefore, in carrying out the activities, devices such as wireless, laptops, LCD projectors, pens, notes and other supporting tools are needed in the form of modules provided.

The activity was held on Monday-Thursday, 18-21 February 2019 from 10:00 to 15:00 WIB, located at the Faculty of Economics and Business, University of Prof. Dr. Moestopo (Religious). The object of this community service is the application and mastery of "Jurnal" software by the community, students and UMKMs as the parties participating in the community service. 


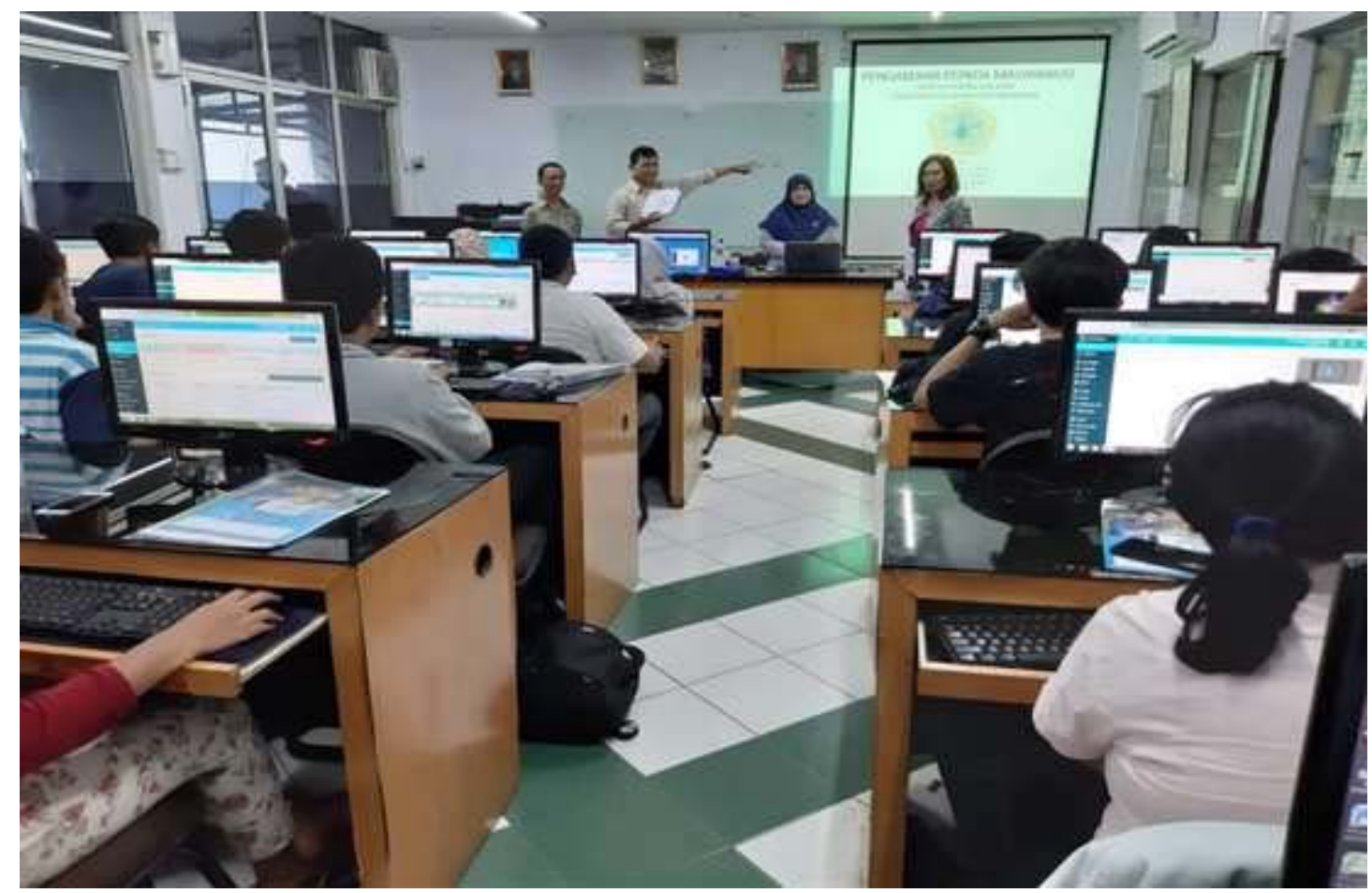

Picture 2. Opening Session

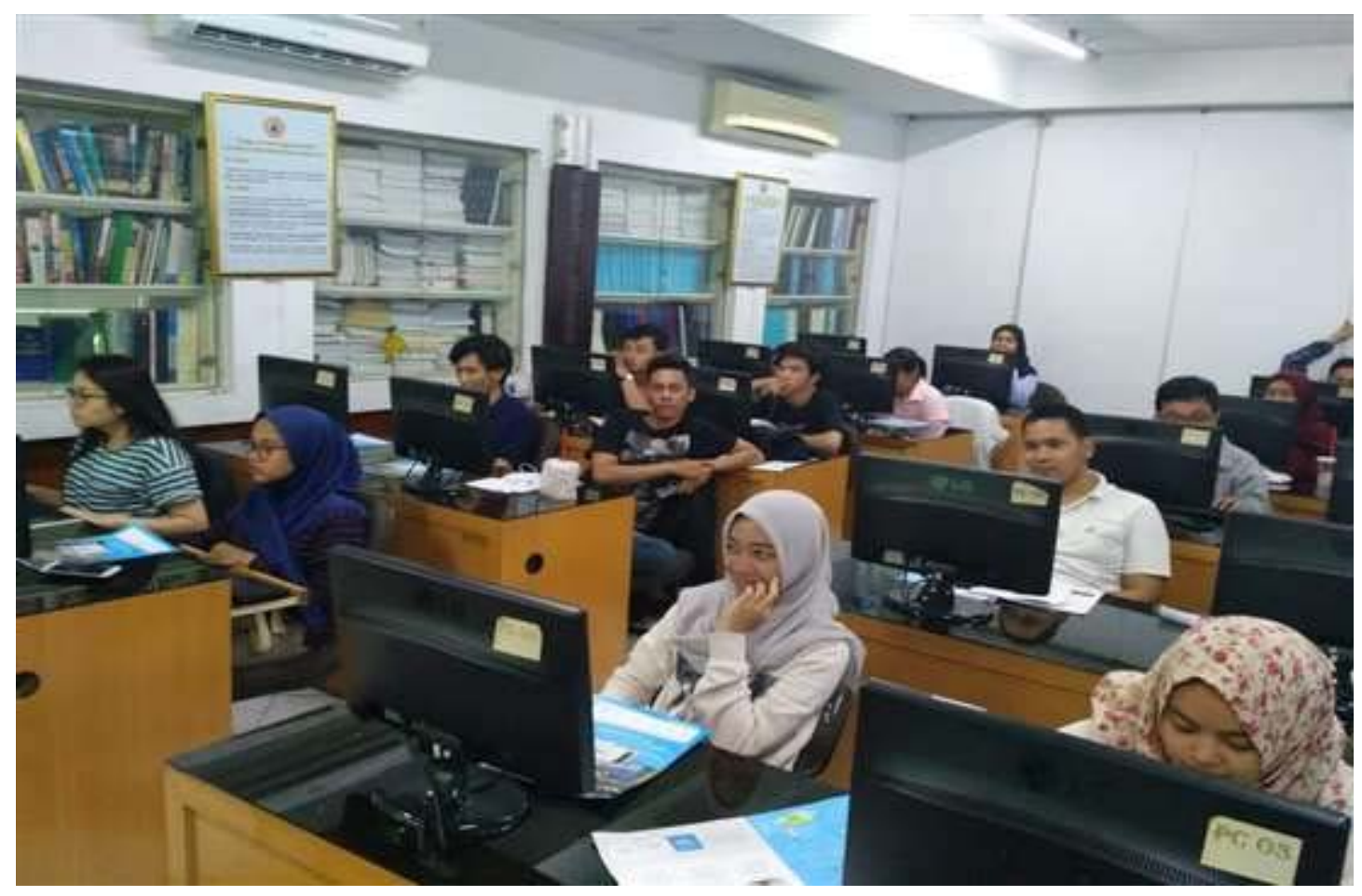

Picture 3. Learning Session 


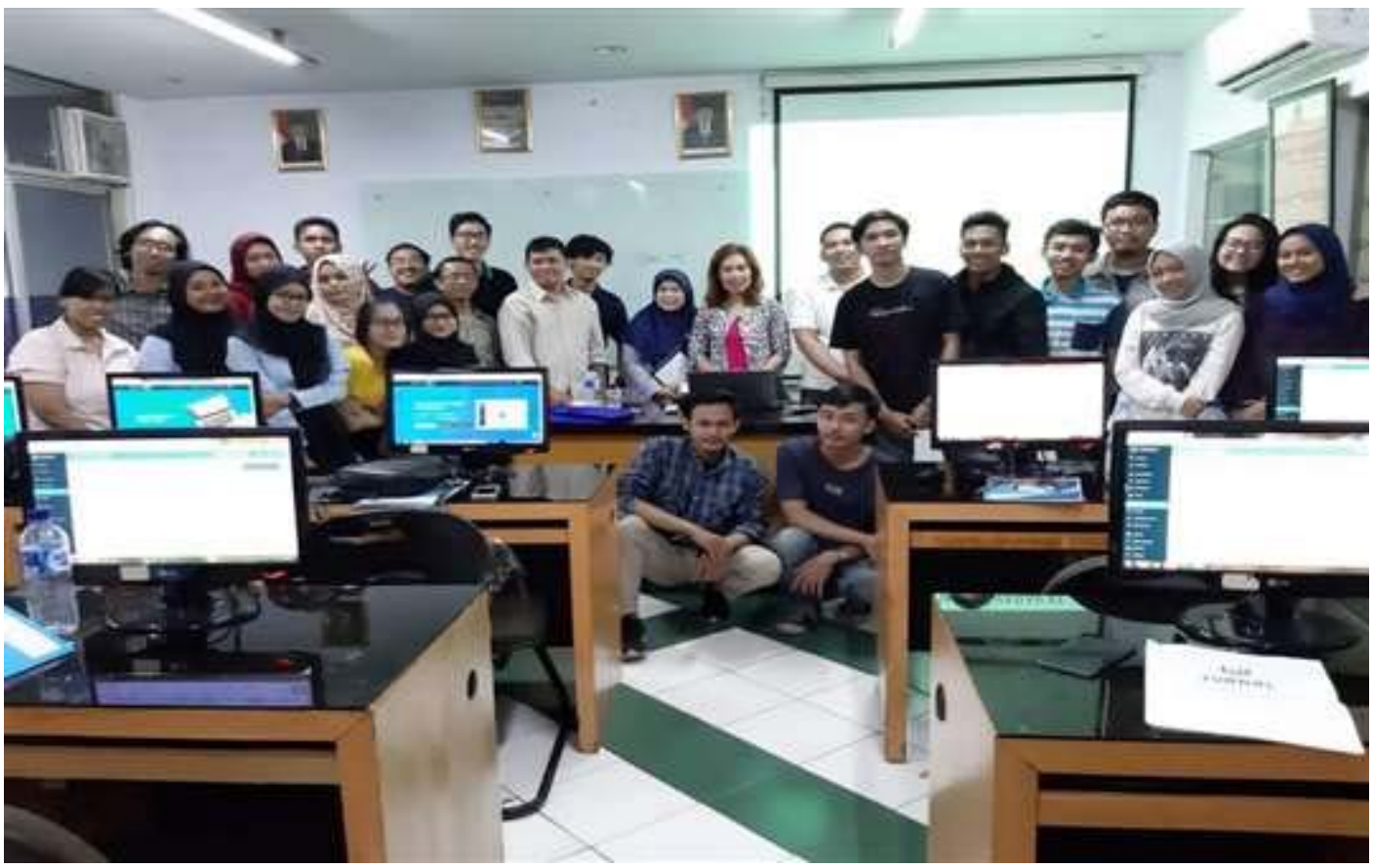

Picture 4. After Examination Session (discussion)

\section{RESULTS AND DISCUSSION}

In carrying out this PKM activity, PKM team worked together in dividing the tasks that have been done previously, mapping and identification by the team including these stages:

\section{Participant inventory}

The inventory of the participants in taking PKM was adjusted to the room capacity determined to be a maximum of 30 participants, as well as the duration of learning and training applied as it would have an impact on the concentration levels of the participants and the material provided. Prolonged training will result in boredom and reduced or even loss of the concentration level of the participants who ultimately do not achieve maximum results. For this reason, the PKM team decided to provide training at 10:00 to 15.00 WIB interspersed with time for prayer and lunch. Each team has roles and tasks through the division of tasks that have been conditioned before.

\section{Introduction to basic accounting}

Before the software training began, participants were given an understanding and learning about accounting records and reporting. Students were included within the training participants with the aim to provide assistance to the PKM team if there were other participants who did not understand the recording system in accounting because all participants did not necessarily understand accounting records well. The introduction of accounting recording theory discussed how to do a journal on business transactions that commonly exist and are used. Based on the activities that have been carried out, there were still some participants who did not understand the logic of accounting recording (debit and credit). The introduction of accounting is very important to operate the system in the software.

\section{Introduction to system}

The recording system through jurnal software is a cloud-based recording system that is integrated with the internet, in other words this software is not on the users' computer desktop or laptop but is available online and on the internet. Jurnal.id can also connect business owners with professional accountants who will assist businesses to manage and arrange their financial plans and save time from administrative and operational processes at an efficient, fast, and effective price so they can focus more on developing their businesses. Thus using this internetbased software makes it easy for users to post into bookkeeping. For entrepreneurs (MSMEs) it will be easier for them to recognize transactions and make posts in journals provided by this software.

\section{Training}

This four-day training provided knowledge to the audience/participants. The participants joined this training with enthusiasm every day it was held, from participants in different educational backgrounds and 
knowledge which caused different responsiveness. Most students found it easier to understand and apply the information system (software) and run it. The training carried out for four days was found to be very effective, this can be proven by the fairly good test results of the participants. The test results were then given as a reference to the software manufacturer and they will be given recommendations for internships in the specified companies (especially students).

\section{CONCLUSIONS}

Based on the activity results, the PKM carried out by the PKM Team from FEB UPDM (B) greatly added value to all participants who participated in the activities (the community, students and MSMEs). These provided added value for them in the field of operating accounting software easily and inexpensively but safely which enhances enthusiasm to share that information to other colleagues. Thus, the role of TAM theory is very appropriate, as it sees projections and uses (security, ease and convenience) resulting from the use of this system, the interest to use accounting software especially the "Jurnal". This then emerged and changed the behaviors of the users who originally did the bookkeeping manually, then chose to switch to using online because the facility is very helpful for the job.

With the implementation of community service, it will bring benefits to all elements (community, students and businesses/UMKMs) and it is better to hold this activity continuously aiming at being able to use the recording system through similar software or other, with the number and frequency of activities more frequent especially in the business sector (MSME). This is very useful to improve the quality of financial statements and human resources currently competing in the era of the industrial revolution 4.0, where industries and human resources are very important to have advantages in their fields in winning the competition of the industry.

With the implementation of community service, it will bring benefits to all elements (community, students and business / UMKM) which will be better to hold this activity continuously. can use the system of recording through similar software or with other with the number and frequency of activities that are more frequent, especially in the business sector (UMKM). This is very useful to improve the quality of financial reports and human resources currently competing in the industrial revolution 4.0 era, where industries and human resources are very important to have an advantage in their fields in winning the competition of the industry.

\section{REFERENCES}

Ajzen, I. 1991. The Theory of Planned Behavior. Organizational Behavior and Human Decision Processes 50, pp. 179-211

Davis, F.D., 1989. Bagozzi, R.P., Warshaw, P.R. User Acceptance of Computer Technology: A Comparison of Two Theoretical Models. Management Science, 35, 8

http://sumberdaya.ristekdikti.go.id, 30-01-2018

https://www.jurnal.id/id/blog/2018 